\title{
Mechanism of Effect of Hypoxia on Renal Water Excretion
}

\author{
Robert J. Anderson, Richard G. Pluss, Arnold S. Berns, James T. Jackson, \\ Patricia E. ARNold, Robert W. Schrier, and Keith M. MCDonald, \\ Department of Medicine, University of Colorado Medical Center, Denver, \\ Colorado 80220
}

A B S T RAC T The effect of lowering the pressure of oxygen from 80 to $34 \mathrm{~mm} \mathrm{Hg}$ was examined in anesthetized dogs that were undergoing a water diuresis. This degree of hypoxia was associated with an antidiuresis as urine osmolality (Uosm) increased from 107 to 316 mosmol/kg $\mathrm{H}_{2} \mathrm{O}(P<0.001)$ and plasma arginine vasopressin increased from 0.06 to $7.5 \mu \mathrm{U} / \mathrm{ml},(P<0.05)$. However, hypoxia was not associated with significant changes in cardiac output (CO, from 4.2 to 4.7 liters/ $\mathrm{min}$ ), mean arterial pressure (MAP, from 143 to 149 $\mathrm{mm} \mathrm{Hg}$ ), glomerular filtration rate (GFR, from 46 to $42 \mathrm{ml} / \mathrm{min}$ ), solute excretion rate (SV, from 302 to 297 $\mathrm{mosmol} / \mathrm{min}$ ), or filtration fraction (from 0.26 to 0.27 , NS). Hypoxia was associated with an increase in renal vascular resistance (from 0.49 to $0.58 \mathrm{~mm} \mathrm{Hg} / \mathrm{ml}$ per min, $P<0.01)$. The magnitude of hypoxia-induced antidiuresis was the same in innervated kidneys and denervated kidneys. To further examine the role of vasopressin in this antidiuresis, hypoxia was induced in hypophysectomized animals. The effect of hypoxia on CO, MAP, GFR, SV, and renal blood flow in hypophysectomized animals was the same as in intact animals. In contrast to intact animals, however, hypoxia did not induce a significant antidiuresis in hypophysectomized animals (Uosm from 72 to $82 \mathrm{mosmol} / \mathrm{kg}$ $\mathrm{H}_{2} \mathrm{O}$ ). To delineate the afferent pathway for hypoxiastimulated vasopressin release, hypoxia was induced in dogs with either chemo- or baroreceptor denervation. The effect of hypoxia on CO, MAP, GFR, SV, and renal blood flow in the denervated animals was the same as in nondenervated animals. Hypoxia resulted in an antidiuresis in chemoreceptor (Uosm from 113 to 357 mosmol $/ \mathrm{kg} \mathrm{H}_{2} \mathrm{O}, P<0.001$ ) but not in baroreceptor (Uosm from 116 to $138 \mathrm{mosmol} / \mathrm{kg} \mathrm{H}_{2} \mathrm{O}$, NS) denervated animals. To determine if hypoxia alters renal response to vasopressin, exogenous vasopressin was adminis-

Dr. Anderson is a recipient of National Institutes of Health Research Career Development award 1 KO4 HLO0 316-01. Dr. Berns is a recipient of a Fellowship of the Kidney Foundation of the Rocky Mountain Region.

Received for publication 26 September 1977 and in revised form 25 May 1978. tered to normoxic and hypoxic groups of dogs. The antidiuretic effect of vasopressin was no different in these two groups. These results demonstrate that hypoxia induces an antidiuresis which is independent of alterations in CO, MAP, SV, filtration fraction, renal nerves, or renal response to vasopressin and occurs through baroreceptor-mediated vasopressin release. The nature of the baroreceptor stimulation remains to be elucidated.

\section{INTRODUCTION}

The effect of hypoxia on renal water excretion has not been clearly delineated. Such an effect has been suggested, however, because chronically hypoxic patients with lung disease may be unable to normally excrete a water load (1-5). Although this defect in water excretion is variable and does not correlate with the degree of hypoxia (2-5), it has been reported to be improved by the administration of oxygen (1). Even so, because hypoxic patients often have cardiopulmonary disease and impaired renal hemodynamics, it is difficult to delineate the specific role of hypoxia in any abnormality of water excretion. Thus, interpretation of the effect of hypoxia on renal water excretion is quite difficult in clinical studies of hypoxic patients with cardiopulmonary disease.

In normal human volunteers and experimental animals, induction of hypoxia has been reported to result in increased (6-12), decreased $(6,13-15)$, and unchanged (16) urine flow. This variability of the effect of hypoxia on urine flow may be related to differences in the degree of hypoxia, in the magnitude of associated renal hemodynamic alterations $(7,17-22)$, in the variable effects of hypoxia on solute excretion $(3,8-10$, 14), or in associated abnormalities in arterial $\mathrm{pH}$ and pressure of carbon dioxide $\left(\mathrm{PCO}_{2}\right)(10,11)$. In view of these contradictory findings, the present study was undertaken to determine the effect of hypoxia on renal water excretion in a setting in which arterial $\mathrm{pH}$ and $\mathrm{PCO}_{2}$ were maintained constant and systemic and renal hemodynamics were monitored. 


\section{METHODS}

Studies were performed on 56 mongrel dogs of either sex that weighed $25-30 \mathrm{~kg}$. Food was withheld $18 \mathrm{~h}$ before the experiment and all animals had free access to water. The animals were anesthetized with intravenous pentobarbital (20-30 $\mathrm{mg} / \mathrm{kg}$ ), intubated, and ventilated with room air with a Harvard respirator (Harvard Apparatus Co., Inc., Millis, Mass.). Ventilator tidal volume was set at $15-20 \mathrm{ml} / \mathrm{kg}$ body weight, and ventilator rate was adjusted to maintain normal alveolar ventilation $\left(\mathrm{PCO}_{2}\right.$ of $\left.25-35 \mathrm{~mm} \mathrm{Hg}\right)$. Anesthesia was maintained throughout the experiment by administration of supplemental doses of pentobarbital.

After induction of anesthesia, polyethylene catheters were inserted into both ureters and renal veins through bilateral flank incisions via a retroperitoneal approach. A catheter was placed in the aorta via the brachial artery for continuous monitoring of arterial pressure with Statham transducers (Statham Instruments, Inc., Oxnard, Calif.) and for frequent sampling of arterial blood gases which were measured with a Corning Blood Gas Analyzer (Corning Medical, Corning Glass Works, Medfield, Mass.). Catheters also were placed in the right atrium via an external jugular vein for injection of cardiogreen dye (Hynson, Wescott \& Dunning, Inc., Baltimore, Md.) to determine cardiac output $(\mathrm{CO})^{1}$ as previously described (23) and in a limb vein for infusion of fluid, inulin, and paraaminohippuric acid. In several studies, one kidney was denervated by stripping all visible nerves and adventitia from the renal pedicle and by applying $95 \%$ alcohol.

During surgery, animals were administered $2.5 \%$ dextrose at 10-15 $\mathrm{ml} / \mathrm{min}$ for $60-90 \mathrm{~min}$ to produce a stable, hypotonic urine flow. Thereafter, $2.5 \%$ dextrose was infused at 2-3 $\mathrm{ml} / \mathrm{min}>$ urine flow. After completion of the above surgery, an intravenous infusion of $0.9 \%$ sodium chloride solution $\mathbf{( 0 . 5}$ $\mathrm{ml} / \mathrm{min}$ ) was started which contained sufficient inulin and para-aminohippuric acid to maintain plasma levels between $15-20 \mathrm{mg} / 100 \mathrm{ml}$ and $1-3 \mathrm{mg} / 100 \mathrm{ml}$, respectively. The experiments were begun 1-2 $\mathrm{h}$ after completion of surgery and stabilization of urine flow. During the experiments, timed urine collections ranged from 5 to $10 \mathrm{~min}$, and arterial and renal venous samples were obtained at the midpoint of alternate urine collection periods. $\mathrm{CO}$ was measured every other collection period. Hypoxia was induced by changing the inspired air mixture from room air to a gas mixture of $10 \%$ oxygen in $90 \%$ nitrogen. In some studies, respiratory rate simultaneously was decreased by $1-3 / \mathrm{min}$. The experiments were carried out according to the following protocols.

Hypoxia in dogs with intact neurohypophyseal tracts and renal nerves: Group I. In these experiments (seven dogs), urine flow was allowed to stabilize, then three to four control periods were obtained. Hypoxia was then induced by lowering the pressure of oxygen $\left(\mathrm{Po}_{2}\right)$ to a mean level of $34 \mathrm{~mm} \mathrm{Hg}$. After 30-60 min of equilibration, another three to four urinecollection periods were obtained during hypoxia. Cessation of hypoxia was followed by another $30-60$-min equilibration period and then three to four post-hypoxia urine collections were obtained.

Hypoxia in dogs with intact neurohypophyseal tracts and one kidney denervated: Group II. Because renal nerves have been postulated to play an important role in the renal

\footnotetext{
${ }^{1}$ Abbreviations used in this paper: AVP, arginine vasopressin; $\mathrm{CH}_{2} \mathrm{O}$, free water clearance; $\mathrm{CO}$, cardiac output; FF, filtration fraction; GFR, glomerular filtration rate; MAP, mean arterial pressure; Posm, plasma osmolality; RVR, renal vascular resistance; $\mathrm{SV}$, solute excretion rate; Uosm, urine osmolality.
}

response to hypoxia $(17,20)$, in these experiments (eight dogs), one kidney in each animal was denervated. The side of denervation was alternated, otherwise the protocol was the same as in group I studies.

In an additional group of six dogs (each with one kidney denervated), a protocol similar to group I studies was carried out. In addition, in these studies the effect of hypoxia on plasma arginine vasopressin (AVP) levels also was assessed. In these studies, blood for AVP determinations was obtained on two to four occasions at 5-min intervals before and 30-60 min after induction of hypoxia.

To insure that hypoxia-induced alterations in ventilation pattern were not responsible for the observed effects of hypoxia on renal water excretion, in six dogs in groups I and II, paralysis with intravenous succinylcholine hydrochloride (1.0 $\mathrm{mg} / \mathrm{min}$ in normal saline; Burroughs Wellcome Co., Research Triangle Park, N. C.) was performed before the start of the control collections and maintained throughout the experiment. The observed effect of hypoxia on any of the measured systemic and renal functional parameters in these paralyzed animals was the same as in nonparalyzed animals. Thus, for statistical analysis, these paralyzed animals were included with nonparalyzed groups I and II animals.

Hypoxia in hypophysectomized dogs: Group III. To determine the physiologic significance of the increases in plasma AVP levels observed in group II animals, experiments (eight dogs) were carried out in acutely hypophysectomized animals in which the source of endogenous AVP had been removed. These animals underwent transbuccal hypophysectomy through the hard palate on the morning of the experiment (24). After hypophysectomy, all animals received dexamethasone $(0.8 \mathrm{mg}$ intramuscular and $0.8 \mathrm{mg}$ intravenous) to avoid any glucocorticoid mediated differences in renal water excretion between intact and hypophysectomized animals. Only hypophysectomized animals which spontaneously exhibited urine osmolalities less than $100 \mathrm{mosmol} / \mathrm{kg} \mathrm{H}_{2} \mathrm{O}$ were used. In addition, none of these hypophysectomized animals had detectable AVP by radioimmunoassay. In five of eight dogs, one kidney was denervated, otherwise the protocol was the same as in group I studies.

Hypoxia in chemoreceptor denervated dogs: Group IV. These studies (six dogs) were performed to examine whether the carotid body chemoreceptor is important in the antidiuretic response to hypoxia (25). In these studies, animals underwent selective denervation of the carotid body chemoreceptor on the morning of the experiment by the method described by Jacobs et al. (26). In all animals, completeness of chemoreceptor denervation was assessed by the disappearance of the hyperpneic and pressor response to i.v. cyanide $(0.3 \mathrm{mg} / \mathrm{kg})$. In an additional two animals, selective carotid chemoreceptor denervation and bilateral cervical vagotomy was carried out. These animals had intact baroreceptors as assessed by maintenance of pressor responses to temporary occlusion of each carotid artery. All kidneys were innervated, otherwise the protocol was the same as in group I studies.

Hypoxia in baroreceptor denervated dogs: Group V. These studies (four animals) were performed to examine whether intact parasympathetic neural pathways are necessary for the antidiuretic effect of hypoxia. On the morning of the experiment, baroreceptor denervation and bilateral cervical vagotomy were carried out as previously described (27). In these animals, completeness of baroreceptor denervation was assessed by abolition of the pressor response to occlusion of each common carotid artery below the level of the carotid sinus that was present before denervation. All kidneys in these animals were innervated, otherwise the protocol was the same as in group I studies.

To examine the role of atrial receptors and aortic arch 
chemoreceptors in the antidiuretic response to hypoxia, the effect of hypoxia on renal water excretion was examined in an additional three animals after bilateral cervical vagotomy. In these animals, the carotid artery baroreceptors remained intact. All kidneys in these animals were innervated, otherwise the protocol was the same as in group I studies.

Studies on the effect of hypoxia on renal response to exogenous vasopressin in hypophysectomized dogs: Group VI. These studies (12 dogs) were carried out to determine if hypoxia alters renal response to exogenous vasopressin. Acutely hypophysectomized, dexamethasone-treated dogs were used. Urine samples for precontrol clearance measurements were obtained. Immediately after these collections, an intravenous bolus of $100 \mathrm{mU}$ vasopressin (Aqueous Pitressin, Parke Davis \& Co., Detroit, Mich.) was administered. After a 10-min equilibration period, experimental clearance periods were obtained. After the effect of vasopressin on urine flow had dissipated, postcontrol urine collections were made. After these collections, six dogs were kept on room air, and six dogs were made hypoxic. $30 \mathrm{~min}$ after the last postcontrol urine collection, precontrol collections periods were again obtained and were followed immediately by a second bolus of $100 \mathrm{mU}$ vasopressin. As before, clearance measurements were started within $10 \mathrm{~min}$ and postcontrol clearance measurements were obtained later, after the effects of vasopressin had disappeared. This protocol allowed the study of the response to two separate injections of vasopressin in dogs with continuous normal $\mathrm{Po}_{2}$ and in dogs made hypoxic before the second vasopressin injection.

Measurement of plasma AVP. Blood was drawn into test tubes that contained EDTA (Vacutainer Tubes, Becton, Dickinson \& Co., Rutherford, N. J.) and centrifuged at $4^{\circ} \mathrm{C}$; the plasma was removed and frozen at $-20^{\circ} \mathrm{C}$. Within 7 days, the plasma was thawed and $1 \mathrm{ml}$ removed. This was acidified with $0.5 \mathrm{ml} 1 \mathrm{~N} \mathrm{HCl}$ and then a $1-\mathrm{ml}(3 \mathrm{mg} / \mathrm{ml})$ suspension of Bentonite (Fisher Scientific Co., Pittsburgh, Pa.) was added (28). The tubes were then vortexed and centrifuged. The supernate was discarded and the Bentonite resuspended in a solution of $1 \mathrm{ml}$ of $80 \%$ acetone in $1 \mathrm{~N} \mathrm{HCl}(28)$. This suspension again was centrifuged, the supernate removed and then washed with $1 \mathrm{ml}$ of ether. The ether layer was aspirated and discarded. The aqueous layer was blown to dryness under room air. The dry residue was then stored at $-20^{\circ} \mathrm{C}$ until it was assayed for AVP.

Radioimmunoassay for AVP. Standard curves were prepared with a U. S. Pharmacopoeia AVP reference preparation (donated by Dr. Rick Weitzman) in quantities that ranged from 0.05 to $10.0 \mu \mathrm{U} /$ assay tube. Each tube was preincubated with a vasopressin antiserum at a final dilution of $1: 247,000$. This antiserum was generously provided by Dr. F. Katz. After $24 \mathrm{~h}$ preincubation of vasopressin with antiserum, $0.1 \mathrm{ml}$ of a solution of ${ }^{125}$ I-labeled AVP (approximately 2,000 cpm) in $0.15 \mathrm{M}$ phosphate buffer was added. The assay mixture was then incubated for a further $48 \mathrm{~h}$ at $4^{\circ} \mathrm{C}$.

Separation of bound from free vasopressin in the assay tubes was performed by the addition of a $0.2-\mathrm{ml}$ suspension of charcoal $\mathbf{( 0 . 5 \%}$ Norit Neutral Charcoal [American Norit Co., Jacksonville, Fla.], 0.1\% Dextran 70 [Cutter Laboratories, Inc., Berkeley, Calif.]). This suspension was centrifuged at $4^{\circ} \mathrm{C}$ for $5 \mathrm{~min}$ at $3,000 \mathrm{rpm}$. The supernate was decantated and the ${ }^{125}$ I radioactivity was counted in both the supernate and charcoal pellet in a Searle model 1285 gamma counter (Searle Diagnostics Inc., Des Plaines, Ill.). Control tubes, incubated without antiserum, provided a measure of nonspecific binding of the ${ }^{125}$ I-AVP.

Antibody specificity. With increasing concentrations of sodium thioglycolate added to the vasopressin standard, a decrease in immunoreactivity was noted. A concentration of
$2.0 \mathrm{M}$ sodium thioglycolate decreased the immunoreactivity of the standard solution by $88.6 \%$. Vasotocin and oxytocin crossreacted by $<0.1 \%$ with the vasopressin antiserum, while lysine vasopressin showed $10 \%$ immunoreactivity when compared with AVP.

Characteristics of the standard curve. $0.05 \mu \mathrm{U} / \mathrm{ml}$ of standard vasopressin consistently produced a $5 \%$ displacement $(\mathrm{B} / \mathrm{Bo} \times 100)$ of the ${ }^{125} \mathrm{I}-\mathrm{AVP}$. The $\mathrm{B}_{50}$ of the standard curve was $0.7 \mu \mathrm{U} / \mathrm{ml}$.

Recovery of AVP from plasma. When standard vasopressin was added to plasma and then extracted with Bentonite, as described above, the recovery of immunoassayable AVP was $79.3 \pm 4.4 \%$ of $n=30$. This recovery was consistent over a range of AVP concentrations between 0.8 and $5.0 \mu \mathrm{U} / \mathrm{ml}$.

Precision and reproducibility of AVP assay. Both intraassay and interassay coefficients of variation were measured at different concentrations of AVP in plasma samples. Intra-assay variation was performed by assaying 120 samples in triplicate. The concentrations of AVP in these plasma samples ranged between 0 and $5.0 \mu \mathrm{U} / \mathrm{ml}$. The coefficient of variation was $6 \%$ at a concentration of $>1.0 \mu \mathrm{U} / \mathrm{ml}$. At a concentration of 0.4 $\mu \mathrm{U} / \mathrm{ml}$, the coefficient of variation was $14 \%$. The interassay variation was determined by performing 14 separate assays on nine plasma samples over a period of $4 \mathrm{mo}$. At a concentration of $1.0 \mu \mathrm{U} \mathrm{AVP} / \mathrm{ml}$ the interassay coefficient of variation was $28.6 \%$, and at a concentration of $4.5 \mu \mathrm{U} / \mathrm{ml}$ the coefficient of variation was $13.7 \%$.

The threshold sensitivity of the assay, which included losses that resulted from the Bentonite extraction, was $0.25 \mu \mathrm{U} / \mathrm{ml}$. This concentration of AVP was significantly different from blank plasma $(P<0.05)$.

The analytical procedures and calculations used in these experiments have been referred to elsewhere $(29,30)$. Student's $t$ test, analysis of variance with the Scheffe modification for multiple comparisons and the Wilcoxon rank sum test were used where appropriate. A $P$ value $<0.05$ was considered significant.

\section{RESULTS}

Effects of hypoxia in dogs with intact neurohypophyseal tract and renal nerves (Table IA). In these studies, as $\mathrm{PO}_{2}$ was lowered from $79.5 \pm 3$ to $32.7 \pm 2$ $\mathrm{mm} \mathrm{Hg}(P<0.001)$, an antidiuresis was observed in each animal as urine osmolality (Uosm) rose from $107 \pm 12$ to $316 \pm 41 \mathrm{mosmol} / \mathrm{kg} \mathrm{H}_{2} \mathrm{O}(P<0.001)$ and fell to $115 \pm 14 \mathrm{mosmol} / \mathrm{kg} \mathrm{H}_{2} \mathrm{O}(P<0.001)$ in the postcontrol period. This effect of hypoxia on Uosm was associated with a significant fall in free water clearance $\left(\mathrm{C}_{\mathrm{H}_{2} \mathrm{O}}\right)$ from $2.15 \pm 0.4$ to $-0.05 \pm 0.2 \mathrm{ml} / \mathrm{min}(P<0.001)$ which rose to $1.92 \pm 0.3 \mathrm{ml} / \mathrm{min}(P<0.001)$ after correction of hypoxia. Hypoxia was not associated with significant alterations in plasma osmolality (Posm) (Posm values before, during, and after hypoxia were $277 \pm 4$, $275 \pm 4$, and $273 \pm 5 \mathrm{mosmol} / \mathrm{kg} \mathrm{H}_{2} \mathrm{O}$, respectively).

The antidiuretic effect of hypoxia was not associated with significant alterations in arterial $\mathrm{pH}$ or $\mathrm{PCO}_{2}$, mean arterial pressure (MAP), CO, glomerular filtration rate (GFR), filtration fraction (FF), or solute excretion rate (SV). Hypoxia was associated with a significant reversible increase in renal vascular resistance (RVR) from $0.493 \pm 0.03$ to $0.575 \pm 0.04 \mathrm{~mm} \mathrm{Hg} / \mathrm{ml}$ per min $(P$ 
TABLE I

Effect of Hypoxia on Arterial Blood Gases, Systemic Hemodynamics, and Renal Function in all Groups of Animals

\begin{tabular}{|c|c|c|c|c|c|c|c|c|c|c|c|c|c|c|c|}
\hline & \multicolumn{3}{|c|}{ MAP } & \multicolumn{3}{|c|}{$\mathrm{CO}$} & \multicolumn{3}{|c|}{ GFR } & \multicolumn{3}{|c|}{ RVR } & \multicolumn{3}{|c|}{ FF } \\
\hline & Pre & Hypox & Post & Pre & Hypox & Post & Pre & Hypox & Post & Pre & Hypox & Post & Pre & Hypox & Post \\
\hline & \multicolumn{3}{|c|}{$m m \mathrm{Hg}$} & \multicolumn{3}{|c|}{ liters/min } & \multicolumn{3}{|c|}{$\mathrm{ml} / \mathrm{min}$} & \multicolumn{3}{|c|}{$\mathrm{mm} \mathrm{Hg} / \mathrm{ml} / \mathrm{min}$} & & & \\
\hline \multicolumn{16}{|c|}{ A. Group I $(n=7)^{*}$} \\
\hline Mean & 143 & 149 & 136 & 4.2 & 4.7 & 3.8 & 45.7 & 42.2 & 46.7 & 0.493 & 0.575 & 0.501 & 0.256 & 0.272 & 0.290 \\
\hline SEM & 6 & 7 & 6 & 0.6 & 0.6 & 0.4 & 4 & 4 & 4 & 0.03 & 0.04 & 0.03 & 0.05 & 0.06 & 0.08 \\
\hline$P$ value & \multicolumn{3}{|c|}{ NS } & \multicolumn{3}{|c|}{ NS } & NS & \multicolumn{2}{|c|}{$<0.05$} & \multicolumn{3}{|c|}{$<0.01<0.05$} & \multicolumn{3}{|c|}{ NS NS } \\
\hline \multicolumn{16}{|c|}{$\begin{array}{l}\text { B. Group II }(n=8) \\
\text { Innervated }\end{array}$} \\
\hline Mean & 139 & 146 & 135 & 4.1 & 4.5 & 4.1 & 45.6 & 44.6 & 54.9 & 0.467 & 0.588 & 0.430 & 0.265 & 0.284 & 0.287 \\
\hline SEM & 6 & 8 & 7 & 0.4 & 0.6 & 0.2 & 4 & 5 & 6 & 0.04 & 0.09 & 0.05 & 0.02 & 0.02 & 0.01 \\
\hline $\begin{array}{c}P \text { value } \\
\text { Denervate }\end{array}$ & \multicolumn{3}{|c|}{ NS } & \multicolumn{2}{|c|}{ NS } & NS & NS & \multicolumn{2}{|c|}{$<0.05$} & \multicolumn{3}{|c|}{ NS NS } & \multicolumn{3}{|c|}{ NS NS } \\
\hline Mean & & & & & & & 46.5 & 49.6 & 50.3 & 0.460 & 0.500 & 0.453 & 0.265 & 0.292 & 0.281 \\
\hline SEM & & & & & & & 3 & 4 & 4 & 0.04 & 0.04 & 0.05 & 0.03 & 0.02 & 0.02 \\
\hline$P$ value & & & & & & & \multicolumn{3}{|c|}{ NS } & \multicolumn{3}{|c|}{ NS NS } & \multicolumn{3}{|c|}{ NS $N$} \\
\hline \multicolumn{16}{|c|}{ C. Group III $(n=8)$} \\
\hline Mean & 130 & 135 & 129 & 3.9 & 3.8 & 3.3 & 30.3 & 29.7 & 30.0 & 0.687 & 0.773 & 0.844 & 0.255 & 0.273 & 0.294 \\
\hline SEM & 7 & 8 & 10 & 0.2 & 0.2 & 0.3 & 3 & 3 & 2 & 0.06 & 0.07 & 0.10 & 0.01 & 0.01 & 0.01 \\
\hline$P$ value & \multicolumn{3}{|c|}{ NS } & $\mathbf{N}$ & & NS & $\mathbf{N}$ & & JS & $\mathbf{N}$ & $\mathbf{S} \quad \mathbf{N}$ & & $\mathbf{N}$ & IS N & vS \\
\hline D. Group IV & & & & & & & & & & & & & & & \\
\hline Mean & 169 & 164 & 144 & 4.6 & 3.7 & 5.1 & 38.6 & 38.4 & 43.7 & 0.952 & 0.963 & 0.713 & 0.401 & 0.418 & 0.382 \\
\hline SEM & 7 & 6 & 9 & 0.9 & 0.2 & 0.1 & 2 & 3 & 2 & 0.07 & 0.10 & 0.10 & 0.03 & 0.05 & 0.02 \\
\hline$P$ value & NS & $N$ & & $\mathbf{N}$ & & NS & NS & & 0.05 & $\mathbf{N}$ & $\mathbf{S} \quad \mathbf{N}$ & vS & $\mathbf{N}$ & $\mathbf{S} \quad \mathbf{N}$ & vS \\
\hline E. Group V ( $r$ & & & & & & & & & & & & & & & \\
\hline Mean & 178 & 177 & 158 & 4.5 & 4.2 & 3.1 & 43.4 & 41.5 & 41.3 & 0.808 & 0.914 & 0.753 & 0.320 & 0.314 & 0.318 \\
\hline SEM & 4 & 2 & 22 & 0.6 & 0.8 & 0.4 & 4 & 5 & 6 & 0.13 & 0.19 & 0.08 & 0.01 & 0.01 & 0.01 \\
\hline$P$ value & NS & $\mathrm{N}$ & $\mathbf{S}$ & $\mathbf{N}$ & & NS & $\mathrm{N}$ & & vS & $\mathbf{N}$ & $\mathbf{S} \quad \mathbf{N}$ & JS & $\mathbf{N}$ & $\mathbf{S} \quad \mathbf{N}$ & NS \\
\hline
\end{tabular}

${ }^{*} n$ refers to the number of dogs in each group. In each dog, results from both kidneys were studied.

$<0.01)$ which fell to $0.501 \pm 0.03 \mathrm{~mm} \mathrm{Hg} / \mathrm{ml}$ per min $(P<0.05)$ after hypoxia.

Effect of hypoxia in dogs with intact neurohypophyseal tracts and one kidney denervated (Table IB). Studies were performed on these animals to evaluate the role of renal nerves in hypoxia-induced antidiuresis. In this group of animals, as $\mathrm{PO}_{2}$ was lowered from $72.8 \pm 0.4$ to $35.1 \pm 2 \mathrm{~mm} \mathrm{Hg}(P<0.001)$, an antidiuresis was again observed in each animal. The increase in Uosm with hypoxia in innervated kidneys was from $83 \pm 5$ to $257 \pm 37 \mathrm{mosmol} / \mathrm{kg}_{2} \mathrm{O}(P<0.001)$ and in denervated kidneys from $73 \pm 2$ to $196 \pm 39 \mathrm{mosmol} / \mathrm{kg}$ $\mathrm{H}_{2} \mathrm{O}(P<0.005)$. Parallel significant reversible decreases in $\mathrm{C}_{\mathrm{H}_{2} \mathrm{O}}$ were observed. There was no statistically significant difference in the magnitude of antidiuresis when either Uosm or $\mathrm{C}_{\mathrm{H}_{2} \mathrm{O}}$ values of innervated and denervated kidneys were compared by paired $t$ test. In these animals, hypoxia was not associated with significant alterations in $\mathrm{PCO}_{2}, \mathrm{pH}, \mathrm{CO}, \mathrm{MAP}, \mathrm{GFR}$, RVR, FF, or SV (Table IB). Posm values before, during, and after hypoxia were $275 \pm 3,272 \pm 3$, and $268 \pm 4$ mosmol/ $\mathrm{kg} \mathrm{H}_{2} \mathrm{O}$, respectively and were not significantly different.

In a separate group of six dogs, $\mathrm{PO}_{2}$ was reduced from $82 \pm 4$ to $34 \pm 5 \mathrm{~mm} \mathrm{Hg}(P<0.001)$. In these animals, Uosm rose from $102 \pm 10$ to $625 \pm 156 \mathrm{mosmol} / \mathrm{kg} \mathrm{H}_{2} \mathrm{O}$ $(P<0.02)$ in innervated kidneys and from $99 \pm 10$ to $608 \pm 156 \mathrm{mosmol} / \mathrm{kg} \mathrm{H}_{2} \mathrm{O}(P<0.02)$ in denervated kidneys. Although these Uosm values are higher than in other groups I and II animals, the increase in Uosm with hypoxia in this group was variable and ranged from 15 to $910 \mathrm{mosmol} / \mathrm{kg} \mathrm{H}_{2} \mathrm{O}$. A significant increment in plasma AVP was observed in each animal as mean plasma AVP levels increased from $0.06 \pm 0.2$ to $7.55 \pm 3.0$ $\mu \mathrm{U} / \mathrm{ml}(P<0.05)$. There was no significant alterations in $\mathrm{PCO}_{2}$ (from $26 \pm 2$ to $27 \pm 1 \mathrm{~mm} \mathrm{Hg}, \mathrm{NS}$ ), $\mathrm{pH}$ (from 7.41 \pm .03 to $7.39 \pm 0.02, \mathrm{NS}$ ), or MAP (from $147 \pm 8$ to $148 \pm 9$ $\mathrm{mm} \mathrm{Hg}, \mathrm{NS}$ ) with hypoxia. In addition, no significant alteration in GFR, RVR, FF, or SV were observed with hypoxia in either innervated or denervated kidneys. Posm values before and during hypoxia were not significantly different $(283 \pm 5$ and $280 \pm 6 \mathrm{mosmol} / \mathrm{kg}$ 


\begin{tabular}{|c|c|c|c|c|c|c|c|c|c|c|c|c|c|c|c|c|c|}
\hline \multicolumn{3}{|c|}{ SV } & \multicolumn{3}{|c|}{ Uosm } & \multicolumn{3}{|c|}{$\mathrm{C}_{\mathrm{H}_{3} \mathrm{O}}$} & \multicolumn{3}{|c|}{$\mathbf{P}_{\mathbf{O}_{\mathbf{2}}}$} & \multicolumn{3}{|c|}{$\mathbf{P}_{\mathrm{CO}_{3}}$} & \multicolumn{3}{|c|}{ pH } \\
\hline Pre & Hypox & Post & Pre & Hypox & Post & Pre & Hypox & Post & Pre & Hypox & Post & Pre & Hypox & Post & Pre & Hypox & Post \\
\hline \multicolumn{3}{|c|}{$\mathrm{mosmol} / \mathrm{min}$} & \multicolumn{3}{|c|}{ mosmol/kg $\mathrm{H}_{2} \mathrm{O}$} & \multicolumn{3}{|c|}{$\mathrm{ml} / \mathrm{min}$} & \multicolumn{3}{|c|}{$m m \mathrm{Hg}$} & \multicolumn{3}{|c|}{$m m \mathrm{Hg}$} & & & \\
\hline 302 & 297 & 275 & 107 & 316 & 115 & 2.15 & -0.05 & 1.92 & 79.5 & 32.7 & 76.1 & 26.7 & 25.9 & 25.6 & 7.39 & 7.41 & 7.42 \\
\hline 30 & 32 & 22 & 12 & 41 & 14 & 0.4 & 0.2 & 0.3 & 3 & 2 & 3 & 0.7 & 0.9 & 1.1 & 0.01 & 0.01 & 0.01 \\
\hline $\mathbf{N}$ & \multicolumn{2}{|c|}{$S \quad$ NS } & \multicolumn{3}{|c|}{$<0.001<0.001$} & \multicolumn{3}{|c|}{$<0.001<0.001$} & \multicolumn{3}{|c|}{$<0.001<0.001$} & \multicolumn{3}{|c|}{ NS NS } & \multicolumn{3}{|c|}{ NS NS } \\
\hline 297 & 323 & 344 & 83 & 257 & 118 & 2.55 & 0.89 & 2.17 & 72.8 & 35.1 & 73.7 & 26.9 & 24.0 & 25.1 & 7.37 & 7.41 & 7.40 \\
\hline 56 & 79 & 77 & 5 & 37 & 16 & 0.6 & 0.6 & 0.4 & 4 & 2 & 4 & 1.1 & 1.4 & 1.9 & 0.01 & 0.01 & 0.01 \\
\hline \multicolumn{3}{|c|}{ NS } & \multicolumn{3}{|c|}{$<0.001<0.005$} & \multicolumn{3}{|c|}{$<0.005 \quad<0.05$} & \multicolumn{3}{|c|}{$<0.001$} & \multicolumn{3}{|c|}{ NS NS } & \multicolumn{2}{|c|}{$<0.01$} & NS \\
\hline 308 & 338 & 320 & 73 & 196 & 125 & 3.09 & 1.38 & 2.25 & & & & & & & & & \\
\hline 50 & 72 & 60 & 2 & 39 & 34 & 0.5 & 0.7 & 0.6 & & & & & & & & & \\
\hline \multicolumn{3}{|c|}{ NS NS } & \multicolumn{2}{|c|}{$<0.05$} & NS & \multicolumn{3}{|c|}{$<0.005 \quad$ NS } & & & & & & & & & \\
\hline 184 & 188 & 192 & 72 & 82 & 88 & 2.16 & 2.03 & 1.72 & 83.8 & 33.7 & 84.8 & 26.3 & 25.0 & 27.1 & 7.38 & 7.41 & 7.37 \\
\hline 17 & 21 & 17 & 7 & 12 & 9 & 0.3 & 0.3 & 0.2 & 4 & 2 & 8 & 2 & 2 & 2 & 0.02 & 0.02 & 0.02 \\
\hline \multicolumn{3}{|c|}{ NS NS } & \multicolumn{3}{|c|}{ NS } & \multicolumn{3}{|c|}{ NS NS } & \multicolumn{2}{|c|}{$<0.001$} & $<0.001$ & & $\mathbf{S}$ & IS & $\mathbf{N}$ & & NS \\
\hline 330 & 477 & 506 & 113 & 357 & 141 & 1.82 & -0.55 & 1.47 & 78.6 & 32.5 & 78.9 & 30.6 & 32.4 & 31.9 & 7.37 & 7.37 & 7.37 \\
\hline 62 & 135 & 94 & 15 & 17 & 15 & 0.2 & 0.1 & 0.2 & 4 & 3 & 5 & 1.8 & 1.7 & 2.4 & 0.01 & 0.01 & 0.02 \\
\hline $\mathbf{N}$ & & vS & $<0.0$ & $01<$ & 0.001 & $<0.0$ & & $<0.001$ & $<0.00$ & & $<0.001$ & & S $\quad 1$ & IS & $\mathbf{N}$ & & NS \\
\hline 472 & 493 & 477 & 116 & 138 & 108 & 2.55 & 1.55 & 2.61 & 86.3 & 39.7 & 87.8 & 32.9 & 33.9 & 33.3 & 7.34 & 7.34 & 7.34 \\
\hline 29 & 61 & 64 & 12 & 18 & 5 & 0.5 & 0.3 & 0.5 & 9 & 6 & 7 & 2.4 & 3.2 & 2.0 & 0.04 & 0.03 & 0.04 \\
\hline $\mathbf{N}$ & & vS & $N$ & & NS & $N$ & IS $\quad N$ & NS & $<0.00$ & & $<0.005$ & & S $\quad 1$ & IS & $\mathbf{N}$ & & NS \\
\hline
\end{tabular}

$\mathrm{H}_{2} \mathrm{O}$, respectively). In these animals, a significant correlation between Uosm and plasma AVP levels before and during hypoxia was observed $(r=0.844$, $n=12, P<0.001)$. Because of this correlation, it should be noted that the variation in Uosm in response to hypoxia in the groups I and II may imply a variable AVP secretory response to a similar degree of hypoxia.

Effects of hypoxia in hypophysectomized dogs (group III, Table IC). Studies were performed on this group of dogs to evaluate the physiologic significance of the increase in plasma AVP levels observed in animals with intact neurohypophyseal tracts with hypoxia. In

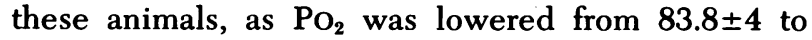
$33.7 \pm 2 \mathrm{~mm} \mathrm{Hg}(P<0.001)$, no significant alteration in either Uosm (from $72 \pm 7$ to $82 \pm 12 \mathrm{mosmol} / \mathrm{kg} \mathrm{H}_{2} \mathrm{O}$, NS) or $\mathrm{C}_{\mathrm{H}_{2} \mathrm{O}}$ (from $2.16 \pm 0.27$ to $2.03 \pm 0.26 \mathrm{ml} / \mathrm{min}$, NS) was observed. Furthermore, in studies performed in six of these animals, no AVP could be detected by radioimmunoassay before or during hypoxia. Hypoxia was not associated with significant alteration in $\mathrm{PCO}_{2}, \mathrm{pH}$, CO, MAP, GFR, RVR, FF, or SV in these animals.
However, these hypophysectomized animals had lower levels of GFR and higher levels of RVR than groups I and II animals, an observation for which we have no explanation. However, these animals have been demonstrated to respond normally to exogenous AVP (31).

Effects of hypoxia in chemoreceptor-denervated dogs with intact neurohypophyseal tracts (group IV, Table ID). Studies were carried out on these animals to determine the role of carotid body chemoreceptors in the antidiuretic response to hypoxia (25). In these animals, as $\mathrm{PO}_{2}$ was lowered from $78.6 \pm 4$ to $32.5 \pm 3$ $\mathrm{mm} \mathrm{Hg}(P<0.001)$, an antidiuresis was observed in each animal as reversible increases in Uosm (from $113 \pm 15$ to $357 \pm 17 \mathrm{mosmol} / \mathrm{kg} \mathrm{H}_{2} \mathrm{O}, \mathrm{P}<0.001$ ) and decreased in $\mathrm{C}_{\mathrm{H}_{2} \mathrm{O}}$ (from $1.82 \pm 0.19$ to $-0.55 \pm 0.14 \mathrm{ml} / \mathrm{min}$, $P<0.001$ ) were observed. Again, hypoxia was not associated with significant alteration in MAP, $\mathrm{CO}, \mathrm{PCO}_{2}, \mathrm{pH}$, GFR, RVR, FF, or SV. However, MAP was higher in these animals than in nondenervated animals, a finding previously noted in chemoreceptor denervated dogs 
(32). Posm values before, during, and after hypoxia were not significantly different at $254 \pm 3,251 \pm 6$ and $248 \pm 6 \mathrm{mosmol} / \mathrm{kg} \mathrm{H}_{2} \mathrm{O}$, respectively. In two additional animals with selective carotid chemoreceptor denervation, bilateral cervical vagotomy, and intact carotid baroreceptors, hypoxia $\left(\mathrm{Po}_{2}\right.$ from $76 \pm 4$ to $\left.38 \pm 2 \mathrm{~mm} \mathrm{Hg}\right)$ was also associated with an antidiuresis as Uosm increased (from $119 \pm 9$ to $323 \pm 175 \mathrm{mosmol} / \mathrm{kg} \mathrm{H}_{2} \mathrm{O}$ ) and $\mathrm{C}_{\mathrm{H}_{2} \mathrm{O}}$ fell (from $2.21 \pm 0.3$ to $-0.12 \pm 0.8 \mathrm{ml} / \mathrm{min}$ ), as GFR (from $38 \pm 6$ to $40 \pm 9 \mathrm{ml} / \mathrm{min}$ ) and RVR (from $0.26 \pm 0.03$ to $0.38 \pm 0.03 \mathrm{~mm} \mathrm{Hg} / \mathrm{ml}$ per $\mathrm{min}$ ) remained constant.

Effects of hypoxia in baroreceptor-denervated dogs with intact neurohypophyseal tract (group V, Table IE). These studies were carried out to determine the role of parasympathetic neural pathways which innervate the carotid baroreceptor in the antidiuretic response to hypoxia. In these studies, as $\mathrm{PO}_{2}$ was lowered from $86.3 \pm 9$ to $39.7 \pm 6 \mathrm{~mm} \mathrm{Hg}(P<0.005)$, no significant alteration in either Uosm (from $116 \pm 12$ to $138 \pm 18$ mosmol $/ \mathrm{kg} \mathrm{H}_{2} \mathrm{O}, \mathrm{NS}$ ) or $\mathrm{C}_{\mathrm{H}_{2} \mathrm{O}}$ (from $2.55 \pm 0.51$ to 1.55 $\pm 0.26 \mathrm{ml} / \mathrm{min}, \mathrm{NS}$ ) was observed. In these animals, hypoxia did not result in significant alteration in MAP, $\mathrm{CO}, \mathrm{PCO}_{2}, \mathrm{pH}, \mathrm{GFR}, \mathrm{RVR}, \mathrm{FF}$, or SV. MAP, however, was significantly higher in these baroreceptor denervated dogs than in nondenervated animals, a finding previously noted by other workers (33). Posm values before, during, and after hypoxia were not significantly different $\left(258 \pm 5,256 \pm 5\right.$ and $253 \pm 4 \mathrm{mosmol} / \mathrm{kg} \mathrm{H}_{2} \mathrm{O}$, respectively). These Posm values were nearly identical to those observed in chemoreceptor denervated (group IV) animals who obtained an antidiuresis with hypoxia. However, to further insure that the hypoosmolality observed in baroreceptor denervated animals did not attenuate vasopressin secretion in response to hypoxia, we examined the antidiuretic response to hypoxia in five intact animals from groups I and II who had significant hypoosmolality (mean Posm of $260 \pm 4 \mathrm{mosmol} / \mathrm{kg}$ $\mathrm{H}_{2} \mathrm{O}$ ). Hypoxia in these animals increased Uosm from $102 \pm 10$ to $408 \pm 78 \mathrm{mosmol} / \mathrm{kg} \mathrm{H}_{2} \mathrm{O}(P<0.005)$. Thus, hypoosmolality per se in the baroreceptor denervated animals was not responsible for the lack of hypoxiainduced antidiuresis.

In a separate group of three animals subjected to bilateral cervical vagotomy, hypoxia $\left(\mathrm{PO}_{2}\right.$ from $76.2 \pm 10$ to $32.4 \pm 5 \mathrm{~mm} \mathrm{Hg}, P<0.005$ ) was associated with a significant increment in Uosm (from $94 \pm 17$ to $198 \pm 54$ mosmol $/ \mathrm{kg} \mathrm{H}_{2} \mathrm{O}, P<0.05$ ) and a significant fall in $\mathrm{C}_{\mathrm{H}_{2} \mathrm{O}}$ (from $2.39 \pm 0.6$ to $0.67 \pm 0.5 \mathrm{ml} / \mathrm{min}, P<0.001$ ). In these animals, hypoxia was not associated with significant alterations in $\mathrm{pH}, \mathrm{PCO}_{2}, \mathrm{MAP}, \mathrm{CO}, \mathrm{GFR}, \mathrm{FF}$, or solute excretion. Hypoxia was, however, associated with a significant increase in RVR (from $0.56 \pm 0.03$ to $0.73 \pm 0.08 \mathrm{~mm} \mathrm{Hg} / \mathrm{ml}$ per min, $P<0.05$ ).

Effects of hypoxia on renal response to exogenous antidiuretic hormone in hypophysectomized dogs (Fig. 1). Studies were performed in these hypophysecto-

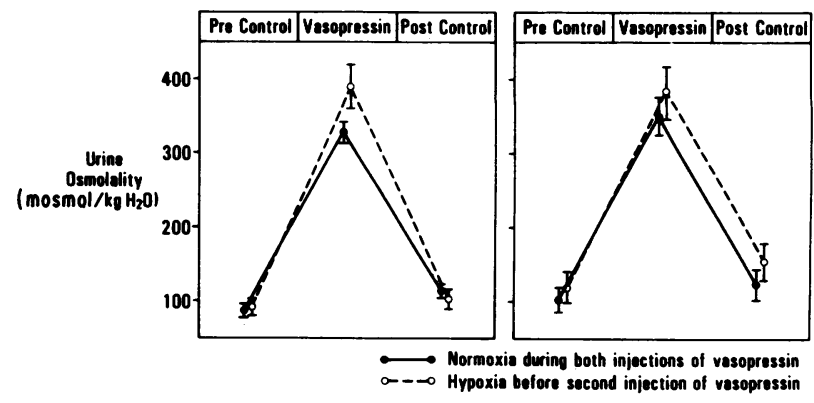

FIGURE 1 Effect of two injections of exogenous vasopressin on urine osmolality in dogs with normal $\mathrm{Po}_{2}$, and in dogs made hypoxic before the second injection of vasopressin.

mized dogs to determine if hypoxia alters renal tubular response to vasopressin. The results are demonstrated in Fig. 1. In the control group of animals, the first injection of vasopressin increased Uosm from $80 \pm 6$ to $330 \pm 11$ mosmol $/ \mathrm{kg} \mathrm{H}_{2} \mathrm{O}(P<0.001)$ which fell to $114 \pm 12$ mosmol/ $/ \mathrm{kg} \mathrm{H}_{2} \mathrm{O}(P<0.001)$. A second injection of vasopressin in the same group of animals increased Uosm from $102 \pm 11$ to $352 \pm 33 \mathrm{mosmol} / \mathrm{kg} \mathrm{H}_{2} \mathrm{O}$ $(P<0.001)$ which fell to $124 \pm 16 \mathrm{mosmol} / \mathrm{kg} \mathrm{H}_{2} \mathrm{O}$ $(P<0.001)$. In the experimental group, the first injection of vasopressin (during normoxia) increased Uosm from $95 \pm 8$ to $382 \pm 49 \mathrm{mosmol} / \mathrm{kg} \mathrm{H}_{2} \mathrm{O}(P<0.001)$, values not significantly different from the control group. After induction of hypoxia $\left(\mathrm{PO}_{2}\right.$ lowered from $77.3 \pm 2$ to $38.8 \pm 2 \mathrm{~mm} \mathrm{Hg}, P<0.001$ ), the same dose of vasopressin increased Uosm from $116 \pm 11$ to $390 \pm 53$ mosmol/ $\mathrm{kg} \mathrm{H}_{2} \mathrm{O}(P<0.001)$. The increment in Uosm after antidiuretic hormone in these hypoxic dogs was not significantly different from the Uosm after the first injection of vasopressin in the same dogs (during normoxia) or from the Uosm of the normoxic control dogs during the second injection of vasopressin. There were no significant alterations in MAP, GFR, RVR, FF, or SV during the six periods in either group of animals.

\section{DISCUSSION}

Previous studies have not clearly delineated the effect of hypoxia on renal water excretion. In earlier studies, associated abnormalities in $\mathrm{pH}$ and $\mathrm{PCO}_{2}$, systemic and renal hemodynamic alterations, and changes in renal solute excretion have not allowed clarification of the effect of hypoxia on renal water excretion. The present study, therefore, was designed to examine the effect of acute hypoxia on renal water excretion. Several groups of experiments were performed to delineate the various factors which might alter renal water excretion during acute hypoxia.

The present results demonstrate that acute hypoxia is associated with a consistent antidiuresis. This antidiuresis occurred in the absence of significant altera- 
tions in renal perfusion pressure, CO, GFR, FF, and $\mathrm{SV}$, factors known to affect tubular fluid reabsorption (34-36). RVR however increased significantly with hypoxia in some experiments. Furthermore, hypoxia may be associated with renal nerve stimulation (17), another factor which may influence tubular fluid reabsorption $(37,38)$. Thus, these intrarenal factors could not be entirely excluded as contributing to the antidiuretic response to hypoxia. Studies were therefore performed in which one kidney was denervated. Renal denervation attenuated the increase in RVR associated with hypoxia yet did not significantly alter the antidiuretic response to hypoxia. These results, therefore, suggested that extrarenal factor(s) primarily mediated the antidiuretic effect of hypoxia.

Because a change in vasopressin release was a potential extrarenal factor, the effect of acute hypoxia on plasma AVP levels was examined. In each animal, an increase in plasma AVP level was observed during acute hypoxia. This finding supports the results in a recent preliminary communication in which a similar degree of hypoxia was associated with significant increments in plasma vasopressin levels as determined by a bioassay technique (39). These findings, however, appear to be at variance with a recent report in which hypoxia did not consistently raise AVP in conscious man (40). In this study, hypoxia induced profound hypocapnia. Because hypocapnia results in venoconstriction and thereby increases central blood volume (41), it is possible that the venoconstrictor effect of hypocapnia served to oppose the AVP stimulatory response of hypoxia. Thus, acute, severe isocapneic hypoxia appears to result in an increase in AVP levels.

To determine the physiological significance of the observed increase in plasma AVP levels, acute hypoxia was induced in acutely hypophysectomized, steroidreplaced dogs that had undectable radioimmunoassayable levels of AVP. Such hypophysectomized animals have been demonstrated to respond normally to exogenous vasopressin (31). Thus, this model has been used successfully to delineate the role of endogenous vasopressin in the antidiuretic response to a variety of stimuli $(24,30,31,42-46)$. In the present study, removal of the source of vasopressin completely abolished the antidiuretic response of hypoxia. In contrast, the antidiuretic response to maneuvers recently performed in our laboratory such as beta adrenergic stimulation (46), thoracic inferior vena cava (30) and portal vein constriction (42) were markedly attenuated but not totally abolished by removal of the source of vasopressin by hypophysectomy. These maneuvers, however, resulted in marked decrements in $\mathrm{CO}$ and(or) MAP which were associated with diminished distal delivery of tubular fluid. Marked alterations in MAP and $\mathrm{CO}$ were not observed in the present study. Thus, the results of the present study suggest that the anti- diuretic effect of hypoxia can be solely attributed to antidiuretic hormone release.

Because no alterations in Posm occurred with hypoxia, further studies were undertaken to examine the nonosmotic pathway whereby hypoxia stimulates vasopressin release. Hypoxia is a known stimulus of carotid body chemoreceptors and a previous study suggested that hypoxia may induce release of vasopressin through carotid chemoreceptor stimulation (25). Furthermore, hypoxia may induce pituitary release of adrenocorticotrophic hormone via stimulation of carotid chemoreceptors (47). Hypoxia therefore was induced in dogs with intact neurohypophyseal tracts but denervated carotid body chemoreceptors. An antidiuretic response to hypoxia was observed in these animals. Further studies were also undertaken to evaluate the possible role of atrial receptors and aortic arch chemoreceptors in the antidiuretic response to hypoxia. In these studies, bilateral cervical vagotomy also did not abolish the antidiuretic response to hypoxia. Taken together, the preservation of the antidiuretic response to hypoxia in carotid artery chemoreceptor denervated dogs and vagotomized dogs suggests that the afferent pathway of hypoxia-induced release of vasopressin does not involve the carotid body chemoreceptor, aortic arch chemoreceptor, or atrial receptors.

The results of recent studies from our laboratory $(31,42,43,46)$ prompted the investigation of whether intact afferent parasympathetic neural pathways are important in hypoxia-induced release of AVP. In these studies performed in dogs with intact neurohypophyseal tracts but denervated baroreceptors, hypoxia did not significantly alter either Uosm or $\mathrm{C}_{\mathrm{H}_{2} \mathrm{O}}$. Thus, these studies suggest that hypoxia may result in release of AVP through induction of alterations in afferent parasympathetic neural tone. In previous studies in which antidiuretic hormone release appeared to be mediated through alterations in afferent parasympathetic tone, decreases in MAP and(or) CO were present $(30,42,46)$. No such alterations in MAP or CO were observed with hypoxia in the present study. Thus, the exact stimulus for baroreceptor-mediated release of AVP remains unclear. However, it is possible that hypoxia results in alterations in sympathetic/parasympathetic interaction. Alternatively, our studies do not exclude a role for baroreceptor/chemoreceptor interaction in modulating hypoxia-induced AVP release (48).

Finally, studies were undertaken to determine if a portion of the antidiuretic effect of hypoxia could be attributable to the effect of hypoxia to alter renal tubular sensitivity to vasopressin. These studies were important because of the demonstrated significance of aerobic metabolism in maximum urinary concentration $(49,50)$. In these studies, an experimental protocol 
previously developed in our laboratory to study the relationship between prostaglandins and vasopressin was utilized (51). Previously, this approach clearly demonstrated an enhanced antidiuretic response to exogenous vasopressin in the absence of prostaglandins (51). However, in the present study, no effect of hypoxia to increase renal response to vasopressin was detected. Thus, these findings suggest that the antidiuretic effect of hypoxia can solely be attributed to AVP release.

In summary, acute, severe hypoxia results in an antidiuresis. This antidiuresis can be disassociated from alterations in systemic hemodynamics, GFR, FF, SV, and renal nerves. The antidiuresis of hypoxia is associated with significant increments in plasma AVP as determined by radioimmunoassay and can be abolished by removing the source of endogenous vasopressin which suggests that this antidiuresis is mediated via secretion of vasopressin. It is also possible, however, that hypoxia results in an alteration in volume of distribution or metabolic clearance rate of vasopressin that could contribute to the elevation in plasma AVP levels with hypoxia. Further studies are needed regarding these possibilities. The afferent pathway for hypoxia-induced release of vasopressin appears to be mediated via afferent parasympathetic pathways and does not involve the carotid sinus chemoreceptor. Finally, hypoxia does not alter renal response to vasopressin.

\section{ACKNOWLEDGMENTS}

We wish to thank Doctors G. Robertson, F. Katz, and R. Weitzman for the invaluable help they gave us in establishing the AVP assay in our laboratory. We would also like to thank Ms. Loretta Durkin for her secretarial assistance.

This study was supported by grants HL 15629 and AMHL 19928, both from the National Institutes of Health.

\section{REFERENCES}

1. Kilburn, K. H., and A. R. Dowell. 1971. Renal function in respiratory failure. Arch. Intern. Med. 127: 754-762.

2. White, R. J., and D. F. Woodings. 1971. Impaired water handling in chronic obstructive airway disease. $\mathrm{Br}$. Med. J. 2: $561-563$.

3. Farber, M. O., T. P. Bright, R. A. Strawbridge, G. L. Robertson, and F. Manfredi. 1975. Impaired water handling in chronic obstructive lung disease. J. Lab. Clin. Med. 85: 41-49.

4. Daggett, P. 1977. An investigation of renal function in chronic bronchitis. Postgrad. Med. J. 53: 24-27.

5. Farber, M. O., S. S. Kiblawi, R. A. Strawbridge, G. L. Robertson, M. H. Weinberger, and F. Manfredi. 1977. Studies on plasma vasopressin and the renin-angiotensinaldosterone system in chronic obstructive lung disease. J. Lab. Clin. Med. 90: 373-380.

6. Stickney, J. C., D. W. Northup, and E. J. Van Liere. 1946. The effect of anoxic anoxia on urine secretion in anesthetized dogs. Am. J. Physiol. 147: 616-621.

7. Silvette, H. 1943. Some effects of low barometric pressures on kidney function in the white rat. Am. J. Physiol. 140: $374-386$
8. Thurau, K. 1961. Renal Na-reabsorption and $\mathrm{O}_{2}$-uptake in dogs during hypoxia and hydrochlorothiazide infusion. Proc. Soc. Exp. Biol. Med. 106: 714-717.

9. Berger, E. Y., M. Galdston, and S. A. Horwitz. 1949. The effect of anoxic anoxia on the human kidney. J. Clin. Invest. 28: 648-652.

10. Ullman, E. 1961. Acute anoxia and the excretion of water and electrolyte. J. Physiol. (Lond.). 155: 416-437.

11. Burrill, M. W., S. Freeman, and A. C. Ivy. 1945. Sodium, potassium, and chloride excretion of human subjects exposed to a simulated altitude of eighteen thousand feet. J. Biol. Chem. 157: 297-302.

12. Currie, J. C. M., and E. Ullman. 1961. Polyuria during experimental modifications of breathing. J. Physiol. (Lond.). 155: 438-455.

13. Franklin, K. J., L. E. McGee, and E. A. Ullman. 1951. Effects of severe asphyxia on the kidney and urine flow. J. Physiol. (Lond.). 112: 43-53.

14. Kaloyanides, G. J., J. D. Cohn, and P. Raskin. 1970. Evidence for increased renal tubule sodium reabsorption in the dogs during hypoxia. Aerosp. Med. 41: 520-524.

15. Granberg, P. O. 1962. Effect of acute hypoxia on renal hemodynamics and water diuresis in man. Scand. J. Clin. Lab. Invest. 14 (Suppl. 63): 1-62.

16. Axelrod, D. R., and R. F. Pitts. 1952. Effect of hypoxia on renal tubular function. J. Appl. Physiol. 4: 593-601.

17. Korner, P. I. 1963. Effects of low oxygen and of carbon monoxide on the renal circulation in unanesthetized rabbits. Circ. Res. 12: 361-374.

18. Bruns, F., and R. Todroff. 1974. Prevention of hypoxic induced decrease in GFR by volume expansion. Clin. Res. 22: 518A. (Abstr.)

19. Aber, G. M. T., J. Bayley, and J. M. Bishop. 1963. Interrelationship between renal and cardiac function and respiratory gas exchange in obstructive airways disease. Clin. Sci. (Oxf.). 25: 159-170.

20. Bruns, F., and K. Losos. 1975. Mechanism of hypoxic induced reduction in glomerular filtration (GFR) and renal plasma flow (RBF). Clin. Res. 23: 356A. (Abstr.)

21. Zillig, B., and B. Truniger. 1977. Renal function and intrarenal hemodynamics in acutely hypoxic rats. Kidney Int. 12: 77. (Abstr.)

22. Guignard, J. P., B. Fillous, and E. Gautier. 1977. Effect of acute hypoxia on renal function in the rabbit. Kidney Int. 12: 75. (Abstr.)

23. Schrier, R. W., and M. H. Humphreys. 1971. Factors involved in the antinatriuretic effects of acute constriction of the thoracic and abdominal inferior vena cava. Circ. Res. 29: 479-489.

24. Schrier, R. W., R. Lieberman, and R. C. Ufferman. 1972. Mechanism of antidiuretic effect of beta adrenergic stimulation. J. Clin. Invest. 51: 97-111.

25. Share, L., and M. N. Levy. 1966. Effect of carotid chemoreceptor stimulation on plasma antidiuretic hormone titer. Am. J. Physiol. 210: 157-161.

26. Jacobs, L., S. R. Sampson, and J. H. Comroe. 1971. Carotid sinus versus carotid body origin of nicotine and cyanide bradycardia in the dog. Am. J. Physiol. 220: 472-476.

27. Berl, T., P. Cadnapaphornchai, J. A. Harbottle, and R. W. Schrier. 1974. Mechanism of suppression of vasopressin during alpha adrenergic stimulation with norepinephrine. J. Clin. Invest. 53: 219-227.

28. Skowsky, W. R., A. A. Rosenbloom, and D. A. Fisher. 1974. Radioimmunoassay of arginine vasopressin: development and application. J. Clin. Endocrinol. Metab. 38: 278-287.

29. Anderson, R. J., M. S. Taher, R. E. Cronin, K. M. McDonald, and R. W. Schrier. 1975. Effect of beta adrenergic block- 
ade and inhibitors of angiotensin II and prostaglandins on renal autoregulation. Am. J. Physiol. 229: 731-736.

30. Anderson, R. J., R. E. Cronin, K. M. McDonald, and R. W. Schrier. 1976. Mechanisms of portal hypertensioninduced alterations in renal hemodynamics, renal water excretion and renin secretion.J. Clin. Invest. 58: 964-970.

31. Schrier, R. W., and T. Berl. 1973. Mechanism of effect of alpha adrenergic stimulation with norepinephrine on renal water excretion. J. Clin. Invest. 52: 502-509.

32. Bernthal, T. 1958. Chemoreflex control of vascular reactions through the carotid body. Am. J. Physiol. 121: 1-20.

33. Edis, A. J. 1971. Aortic baroreflex function in the dog. Am. J. Physiol. 221: 1352-1357.

34. Levinsky, N. G., D. D. Davidson, and R. W. Berliner. 1959. Effects of reduced glomerular filtration on urine concentration in the presence of antidiuretic hormone. J. Clin. Invest. 38: 730-740.

35. Wesson, L. G., Jr., and W. P. Anslow, Jr. 1948. Excretion of sodium and water during osmotic diuresis in the dog. Am. J. Physiol. 153: 465-474.

36. Schrier, R. W., and H. E. de Wardener. 1971. Tubular reabsorption of sodium ion: influence of factors other than aldosterone and glomerular filtration rate. $N$. Engl. J. Med. 285: 1231-1243, 1292-1303.

37. Nomura, G., T. Takabatake, S. Arai, D. Uno, M. Shimao and N. Hattori. 1977. Effect of acute unilateral renal denervation on tubular reabsorption of sodium in the dog. Am. J. Physiol. 232: F16-F19.

38. Bello-Reuss, E., D. L. Trevino, and C. W. Gottschalk. 1976. Effect of renal sympathetic nerve stimulation on proximal water and sodium reabsorption. J. Clin. Invest. 57: 1104-1107.

39. Forsling, M. L., and E. Ullmann. 1974. Release of vasopressin during hypoxia. J. Physiol. (Lond.). 241: 35-36.

40. Baylis, P. H., R. A. Stockley, and D. A. Heath. 1977. Effect of acute hypoxaemia on plasma arginine vasopressin in conscious man. Clin. Sci. Mol. Med. 53: 401-404.
41. Weil, J. V., E. Byrne-Quinn, D. J. Battack, R. F. Grover, and C. A. Chidsey. 1971. Forearm circulation in man at high altitude. Clin. Sci. (Oxf.). 40: 235-246.

42. Anderson, R. J., P. Cadnapaphornchai, J. A. Harbottle, K. M. McDonald, and R. W. Schrier. 1974. Mechanism of effect of thoracic inferior vena cava constriction on renal water excretion. J. Clin. Invest. 54: 1473-1479.

43. Schrier, R. W., and T. Berl. 1972. Mechanism of the antidiuretic effect associated with interruption of parasympathetic pathways. J. Clin. Invest. 51: 2613-2620.

44. Cadnapaphornchai, P., J. Boykin, J. A. Harbottle, K. M. McDonald, and R. W. Schrier. 1975. Effect of angiotensin II on renal water excretion. Am. J. Physiol. 228: 155-159.

45. Cadnapaphornchai, P., J. L. Boykin, T. Berl, K. M. McDonald, and R. W. Schrier. 1974. Mechanism of effect of nicotine on renal water excretion. Am. J. Physiol. 227: 1216-1220.

46. Berl, T., P. Cadnapaphornchai, J. A. Harbottle, and R. W. Schrier. 1974. Mechanism of stimulation of vasopressin release during beta-adrenergic stimulation with isoproternol. J. Clin. Invest. 53: 857-867.

47. Lau, C., and S. F. Marotta. 1969. Role of peripheral chemoreceptors and adrenocortical secretory rates during hypoxia. Aerosp. Med. 49: 1065-1968.

48. Heistad, D. D., F. M. Abboud, A. L. Mark, and P. G. Schmid. 1974. Interaction of baroreceptor and chemoreceptor reflexes. J. Clin. Invest. 53: 1226-1236.

49. Martinez-Maldonado, M., G. Eknoyan, and W. N. Suki. 1969. Effects of cyanide on renal concentration and dilution. Am. J. Physiol. 217: 1363-1368.

50. Martinez-Maldonado, M., G. Eknoyan, and W. N. Suki. 1970. Importance of aerobic and anaerobic metabolism in renal concentration and dilution. Am. J. Physiol. 218: 1076-1081.

51. Anderson, R. J., T. Berl, K. M. McDonald, and R. W. Schrier. 1975. Evidence for an in vivo antagonism between vasopressin and prostaglandin in the mammalian kidney. J. Clin. Invest. 56: 420-426. 